\title{
A SUBFAMÍLIA SCHWENCKIOIDEAE (SOLANACEAE) NO SEMIÁRIDO BRASILEIRO
}

\author{
Aline Gomes Assuncão ${ }^{1}$; Flávio França ${ }^{2}$ \\ 1. Bolsista PIBIC/CNPq, Graduando em Ciências biológicas, Universidade Estadual de Feira de Santana, e-mail: \\ allineg.assuncao@hotmail.com \\ 2. Orientador, Departamento de Ciências Biológicas, Universidade Estadual de Feira de Santana, e-mail: \\ franca.flavio@gmail.com
}

PALAVRAS-CHAVE: Melananthus, Schwenckia e Heteranthia

\section{INTRODUÇÃOO}

A subfamília Schwenckioideae no semiárido é representada pelos gêneros Schwenckia L., Melananthus Walp. e Heteranthia Nees \& Mart.. O gênero Schwenckia L. possui como domínios fitogeográficos a Amazônia, Caatinga, Cerrado, Mata Atlântica, Pantanal. No Brasil ocorrem cerca de 16 espécies (Carvalho, 1978).O gênero Melananthus Walp. possui um domínio fitogeográfico bem similar ao de Schwenckia, não sendo observada a ocorrência do gênero no Pantanal. No Brasil, ocorrem cerca de cinco espécies (Soares, 2006). O gênero Heteranhia é monoespecífco, sendo Heteranthia decipiens Nees \& Mart., exclusiva da flora brasileira, com ocorrência para os estados de Minas Gerais, Rio de Janeiro e Bahia (Carvalho, 1999). As espécies de Schwenckioideae são muito parecidas distinguindo-se principalmente devido ao número de estames e forma do fruto, se coletada apenas com flor, pode ter a identificação dificultada. Para a separação dos gêneros, foi necessário um estudo cuidadoso da subfamília para o semiárido, visando não só o conhecimento da sua ocorrência na área de estudo como também a separação dos gêneros nas coleções dos herbários visitados. O potencial econômico da subfamília Schwenckioideae ainda é desconhecido, por ser uma espécie ruderal de ampla distribuição, sendo facilmente encontrada, Schwenckia americana a mais estudada até então. A planta inteira é utilizada por comunidades tradicionais no Norte da Nigéria para o tratamento do diabetes mellitus, em função desse uso, foi alvo de investigação por Bello et al. (2013), que constatou sua eficiência na redução do açúcar no sangue de ratos com diabetes tipo 2. Nwabunike et al. (2014), elaborou estudos de bioatividade anti-inflamatória da espécie a partir de partes aéreas da planta.

\section{MATERIAL E MÉTODOS}

Expedições foram realizadas pra os estados de Alagoas, Sergipe, Bahia e Pernambuco, no período 2015 a 2016, onde o critério para excursão foi o registro de ocorrência na área, ou nas proximidades, a fim de aumentar as chances de encontrar o material a ser coletado. Todo material coletado na área de estudo foi descrito em planilha Excel, registrado no banco de dados, etiquetado e posteriormente depositado no HUEFS. As plantas foram identificadas utilizando-se literatura especifica da família e por comparação com exsicatas identificadas por outros especialistas. Para avaliação das espécies coletadas por municípios do semiárido, foram utilizados os dados do Species link (CRIA, 2011), onde 1130 municípios foram analisados. Foram feitas visitas a outros herbários além do HUEFS (ALCB, BAH, BHCB, CEPEC, HRB, ASE e HVASF, siglas conforme Thiers, 2014) que auxiliaram na coleta de dados sobre espécies, bem como uma melhor análise do material coletado. 
Os gêneros Schwenckia L. e Melananthus Walp. são facilmente separados pelo fruto, coloração das flores e número de sementes, o que corrobora com Soares (2006), sendo acrescentado apenas número de estames férteis à distinção dos gêneros.

$\mathrm{O}$ gênero Heteranthia distingue-se principalmente devido a coloração e ao formato da corola. O registro da ocorrência de Heteranthia decipiens Nees \& Mart. para o semiárido, restringe-se ao estado da Bahia, com coletas para os municípios de Ubaíra, Jacobina, Bonito, Itaberaba, Lençóis e Mucugê. A espécie foi coletada em Jacobina, próximo à área de cultivo, com flores brancas e frutos verdes imaturos. Foi verificada em quatro herbários visitados, porém em todos eles com baixo número de exemplares. É classificada como vulnerável (VU), correndo risco de extinção, ocupam áreas de risco, como zona de cultivo e regiões de mata com ação antrópica (Carvalho 1999).

Melananthus Walp. está representado no semiárido por três espécies: M. ulei Carvalho, M. cubensis Urb., e M. fasciculatus (Benth.) Soler., sendo M. fasciculatus, endêmico da flora brasileira. A ocorrência do gênero Melananthus foi verificada em três estados do semiárido brasileiro: Bahia, Rio Grande do Norte e Minas Gerais, ocorrendo em oito municípios. Melananthus apresenta quatro estames férteis, didínamos; fruto cápsula rostrada, unilocular; corola marrom ou violácea, semente única com tamanho igual ou superior a $1 \mathrm{~mm}$. Para a separação das espécies foi observado o formato dos apêndices laciniformes, o comprimento do estigma, que em $M$. ulei apresenta-se abaixo dos estames superiores enquanto que $M$. fasciculatus está disposto acima dos estames superiores.

O gênero Schwenckia foi verificado em cinco estados: Bahia, Pernambuco, Paraíba, Rio Grande do Norte e Ceará, com ocorrência em 64 municipios do semiárido, com o registro de sete espécies, sendo elas: $S$. micrantha Benth., S. mollissima Nees \& Mart., $S$. lateriflora (Vahl) Carvalho, S. heterantha Carvalho, S. americana L., S. grandiflora Benth., e $S$. hyssopifolia Benth., que é exclusiva do Brasil tendo registro apenas para a Bahia. As espécies do gênero Schwenckia possuem dois estames férteis e três estaminódios, que se apresentam na forma de longos filetes, (característica morfológica utilizada para a separação dos gêneros), fruto cápsula, bilocular; corola geralmente amarela-esverdeadas ou violáceas; e numerosas sementes com tamanho inferior a $1 \mathrm{~mm}$. A distinção das espécies de Schwenckia foi feita basicamente a partir do número de estames férteis, consistência foliar, formato da corola, presença e formato dos apêndices.

\section{Chave para os gêneros de Schwenckioideae}

1.Corola tubular

2. Estaminódios presentes, cápsula simétrica, não rostrada.........Schwenckia

2'.Estaminódios ausentes, cápsula assimétrica, rostrada .............Melananthus

1'. Corola bilabiada

Heteranthia

\section{Chave para identificação das espécies de Melananthus Walp. do semiárido brasileiro}

1. Corola com 5 apêndices laciniformes iguais

2. Estigma abaixo dos estames superiores. M. ulei

2'. Estigma acima dos estames superiores.... M. fasciculatus

1 '.Corola com 5 apêndices laciniformes desiguais. M. cubensis 


\section{Chave para identificação das espécies de Schwenckia L. do semiárido brasileiro}

1. Estames férteis 4 didínamos

2. Lâmina foliar carnosa

S. hyssopifolia

2'. Lâmina foliar membranácea

3. Corola tubular suburseolada, lobo da corola emarginado sem

apêndice

S. heterantha

3'. Corola tubular reta, lobo da corola emarginado apendiculado, apêndice ovado

S. micrantha

1 '. Estames férteis 2

4. Lâmina foliar linear-lanceolada a elíptica, margem inteira.....S. americana

4'. Lâmina foliar ovado-cordada a oblongo-ovada, margem ciliada

5. Região interpetálica não apendiculada, lacínias longas

atenuadas

S. grandiflora

5'. Região interpetálica apendiculada distalmente

6. Apêndices filiformes ca. 4-5 mm compr., lobo da corola ciliado

S. mollissima

6'. Apêndices filiformes ca. 6-10 mm compr., lobo da corola ovado, ovado ou quase truncado

S. lateriflora

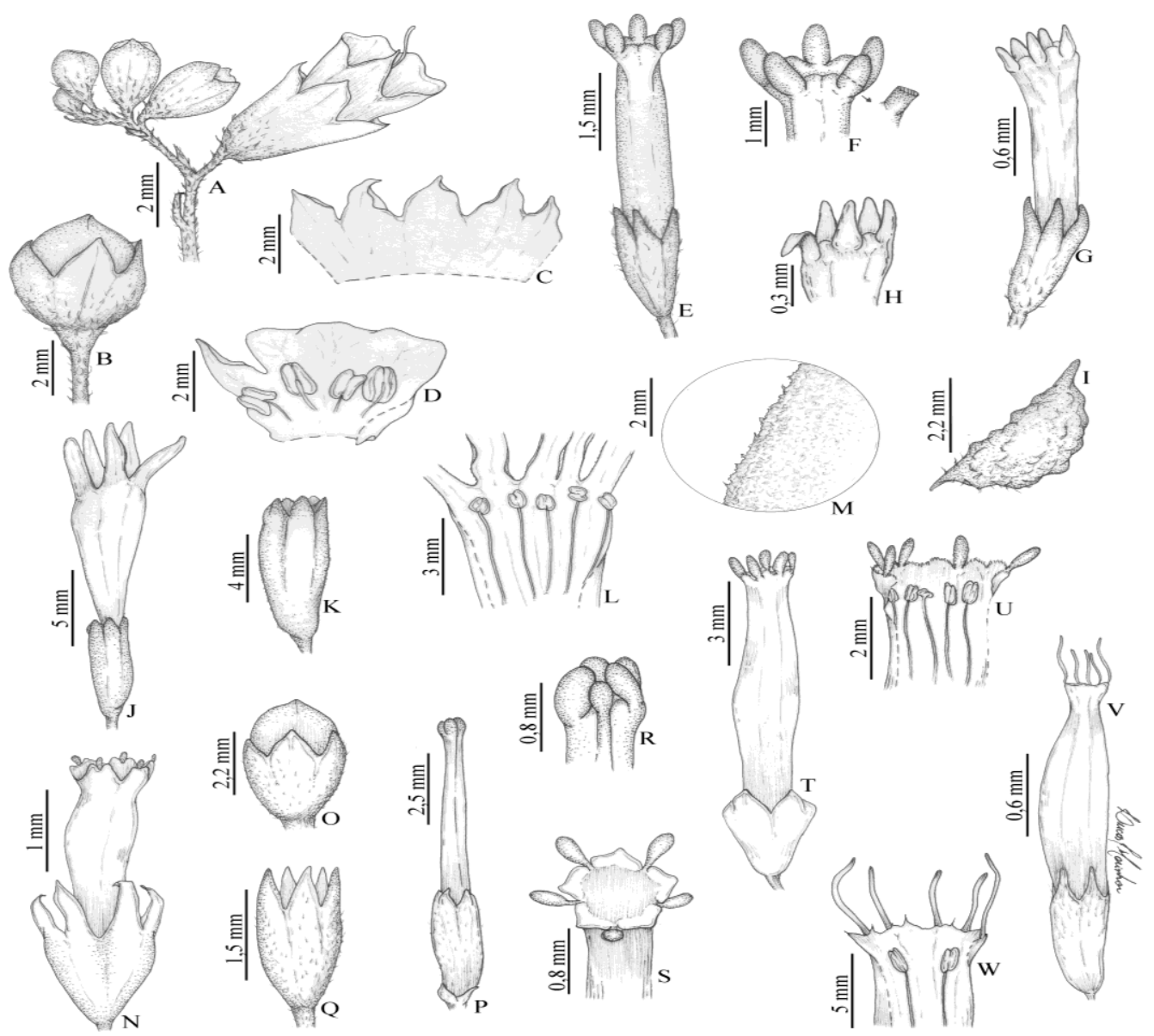

Figura 1. A-D. Heteranthia decipiens: A- ramo com flor e fruto; B- fruto; C- cálice; D- corola, evidenciando os estames; E-F. Melananthus ulei: E- flor, aspecto geral; F- fauce da corola; G-I. Melananthus cubensis: Gflor, aspecto geral; H- fauce da corola; I. fruto; J-M. Schweckia grandiflora: J- flor; K- cálice; L. corola/estames; M- lacínias com margem espaçadamente ciliada; N. Schwenckia micrantha: flor, aspecto geral ; O-S. Schwenckia americana; O-fruto; P- flor, aspecto geral; Q. Cálice; R- fauce da corola fechada; S- Fauce da corola aberta; T-U. Schwenckia heterantha: T- flor, aspecto geral; U- fauce da corola/ estames; V-W. Schwenckia mollissima: V- flor; W- fauce da corola/estames. 


\section{CONSIDERAÇÕES FINAIS (ou Conclusão)}

A subfamília Schwenckioideae está bem representada no Semiárido brasileiro, com a ocorrência de três gêneros, Schwenckia, Melananthus e Heteranthia e pode ser encontrada em diversos ecossistemas, porém poucas coletas foram realizadas para os gêneros. Apesar da proximidade entre os gêneros da subfamília Schwenckioideae, eles podem ser facilmente separados com base no número de estames férteis, fruto e as lacínias da corola.

Este trabalho estabelece a primeira contribuição taxonômica para a subfamília Schwenckioideae no semiárido brasileiro, e fornece subsídios para futuros estudos, bem como propicia a identificação de matérias coletados apenas com flores, visto que as chaves foram elaboradas com enfoque em caracteres florais. A partir deste, pode-se apontar a necessidade de aprofundamento no estudo da subfamília, visto que as espécies são pouco coletadas, e possuem potencial econômico ainda desconhecido.

As coleções dos herbários ainda possuem carência de algumas espécies, devido à ausência de coletas, quando coletadas, muitas delas se encontram com identificações incorretas nos herbários, o que é refletido pela baixa produção científica para a subfamília, necessitando de coletas, estudos filogenéticos, fotoquímicos, histológicos, até mesmo etnobotânicos visto que essas espécies podem ter utilização medicinal por comunidades tradicionais ainda desconhecidas pela ciência, e da continuidade de estudos taxonômicos.

\section{REFERENCIAS}

BELLO SO, C. A. CHIKA, A., JIMOH, A.O., ABUBAKAR, K. AND ADEBISI, I. (2013). Evaluation of hypoglycaemic and antihyperglycaemic activity of methanolic whole plant extract of Schwenckia americana (Solanacae) in normal and alloxaninduced diabetic rats. African Journal of Pharmacy and Pharmacology, 7(39), 26622666.

NWABUNIKE, I. A.; EZIKE, A. C.; NWODO, N. J.; UDEGBUNAM, S. O.; OKOLI, C. O. 2014. Bioactivity-guided studies on the antiinflammatory activity of extract of aerial parts of Schwenckia americana L. (Solanaceae). J. Med. Plants Res.

CARVALHO, L. D'A. F. 1978. O gênero Schwenckia D. Van Rooyen ex Linnaeus no Brasil, Solanaceae. Instituto de Pesquisas Jardim Botânico do Rio de Janeiro. Rodriguésia. v. 29, p.307-524.

CARVALHO, L. D’A. F. 1999. Heteranthia decipiens Nees \& Martius (Solanaceae), uma espécie rara, exclusiva da flora brasileira. Rodriguésia 50(76/77): 77-83.

CRIA (Centro de Referência e Informação Ambiental). 2011. Specieslink - simple search. Disponível em http://www.splink.org.br/index (Acesso em 2016).

SOARES, E. L. DE C. 2006. Estudos taxonômicos em Solanaceae lenhosas no Rio Grande do Sul, Brasil. Universidade Federal do Rio Grande do Sul; Instituto de Biociências, Departamento de Botânica. Programa de Pós-Graduação em Botânica. Porto Alegre.

THIERS, B. [2014 ontinuously updated]. Index Herbariorum: A global directory of public herbaria and associated staff. New York Botanical Garden's Virtual Herbarium.<http://sweetgum.nybg.org/ih/> .Acesso em: 28 Ago. 2016. 